\title{
Investigation of normal flatus production in healthy volunteers
}

\author{
J Tomlin, C Lowis, N W Read
}

\begin{abstract}
Flatulence can cause discomfort and distress but there are few published data of normal patterns and volumes. Twenty four hour collections were made using a rectal catheter in $\mathbf{1 0}$ normal volunteers taking their normal diet plus $200 \mathrm{~g}$ baked beans. Total daily volume ranged from 476 to $1491 \mathrm{ml}$ (median $705 \mathrm{ml}$ ). Women and men (both $n=5$ ) expelled equivalent amounts. The median daily flatus hydrogen volume was $361 \mathrm{ml} / 24 \mathrm{~h}$ (range 42-1060) and the carbon dioxide volume $68 \mathrm{ml} / 24 \mathrm{~h}$ (range 25-116), three volunteers produced methane $(3,26$, and $120 \mathrm{ml} / 24 \mathrm{~h})$, and the remaining unidentified gas (presumably nitrogen) or gases contributed a median $213 \mathrm{ml} / 24 \mathrm{~h}$ (range 61-476). Larger volumes of flatus were produced after meals than at other times. Flatus produced at a faster rate tended to contain more fermentation gases. Flatus was produced during the sleeping period, but the rate was significantly lower than the daytime rate (median 16 and $34 \mathrm{ml} / \mathrm{h}$ respectively). Ingestion of a 'fibre free' diet (Fortisip) for $\mathbf{4 8}$ hours significantly reduced the total volume collected in 24 hours (median $214 \mathrm{ml} / 24 \mathrm{~h}$ ), reduced the carbon dioxide volume (median $6 \mathrm{ml} / 24 \mathrm{~h}$ ), and practically eradicated hydrogen production. The volume of unidentified gas was not significantly affected (median $207 \mathrm{ml} / 24 \mathrm{~h}$ ). Thus fermentation gases make the highest contribution to normal flatus volume. A 'fibre free' diet eliminates these without changing residual gas release of around $200 \mathrm{ml} / 24 \mathrm{~h}$.
\end{abstract}

To most people flatulence, or the passage of gas through the rectum, is a frequent everyday occurrence that causes no distress or discomfort. Some people, however, attend their doctors complaining of excessive flatulence, often associated with severe pain and bloating. Some of these patients produce large amounts of gas and their symptoms can be relieved by dietary modifications. Others may produce more modest volumes and their discomfort may be related to increased sensitivity to gastrointestinal distension or abnormal transit of gases. ${ }^{2}$

Little is known about the normal volume and composition of flatus. The amount of gas produced per day is usually calculated from a shorter collection period, ${ }^{34}$ disregarding the possibility of diurnal variations in gas production or emission. Such diurnal variations are probable since ileocolonic motor patterns, which control the delivery of substrate to the colon and propel gas to the rectum, vary widely throughout the day. ${ }^{5}$ Attempts at more prolonged flatus collections have entailed keeping subjects awake during overnight collections ${ }^{6}$ or confining the subjects to bed during the day, ${ }^{4}$ both of which may have affected the amount of gas produced.

Gas which is passed through the rectum has four possible sources: air that has been swallowed either in combination with food or drink or separately; carbon dioxide formed during the interaction of gastric acid with alkaline secretions or foods; hydrogen, methane, and carbon dioxide formed in the large intestine during bacterial fermentation processes; and gas which diffuses into the lumen from the bloodstream. The composition of flatus should reflect the source of the gases, although the transit rate through the intestines may also affect the final composition of flatus as gaseous equilibration between the gastrointestinal lumen and the blood is a relatively slow process which may be limited by the exposure time. ${ }^{7}$ Similarly, the timing of flatus release may reflect both an increase in the rate of gas production and also an increase in propulsive motor activity.

Substrate for bacterial gas production includes both dietary material which is not digested in the small intestine (principally the complex polysaccharides of starch and dietary fibre) and endogenous sources such as mucins. ${ }^{8}$ The measurement of relative amounts of gas produced from these substrates can elucidate how dietary modifications can influence flatus production.

The aim of our study was to document the volume and composition of flatus gas over a 24 hour period while the volunteers undertook their normal daily activities and consumed their normal diet and also while they consumed a fibre free liquid diet (Fortisip), which contained no complex polysaccharides and so would deprive the bacteria of exogenous substrate.

\section{Methods}

\section{VOLUNTEERS}

Ten healthy volunteers (five men and five women, aged 19-25 years) were recruited for the study. None had suffered from gastrointestinal illness and none had taken antibiotics for six months before the study. They gave written informed consent and the study was approved by the local ethical committee.

\section{PROTOCOL}

Flatus gases were collected over a 24 hour period in 10 subjects during consumption of a normal diet which included $200 \mathrm{~g}$ baked beans in tomato sauce (HP, Market Harborough, Leicestershire) and in six of these subjects while they consumed 
a liquid diet containing no complex polysaccharides.

The collections began between 0900 and 1300 after the volunteers had opened their bowels.

Flatus gas was collected by means of a flexible gas impermeable rubber tube (Butyl XX Tubing, Esco Rubber, Teddington, Middlesex, length $650 \mathrm{~mm}$, external diameter $9 \mathrm{~mm}$ ), the tip of which was inserted $40 \mathrm{~mm}$ into the anus, and held in place either with surgical tape or the subject's underclothes. The other end of the tube was attached to one of the arms of a plastic T-connector which was in turn connected to a laminated gas bag which was impermeable to gas diffusion (1L, Analysis Automation, Oxford, Oxon). The competence of this gas collection system was validated in two volunteers who submerged the lower parts of their bodies in warm water for an hour during which time there were no detectable leaks (bubbling) and gas was collected in the bags.

The gas bags were changed at 30 minute intervals for the first 6 hours, then at hourly intervals until the subjects retired to bed; one bag was used overnight and then after waking hourly changes were made until the 24 hour collection was completed. The volunteers were fully mobile and noted any exercise they undertook.

During the 24 hour collections the volunteers kept a diary of the time of any episodes of flatulence noticed and of bowel movements. If they experienced a need to defecate they were instructed to close off the current gas bag, remove the tube from the anus, defecate, and clean the tip of the tube if necessary with a cotton bud, reinsert the tube, and attach a new bag as quickly as possible.

While on their normal diets the volunteers kept a diary of their food intake using approximate portion sizes for 24 hours before, and during the 24 hours of the study. This was analysed for energy, dietary fibre, and fat content using food tables. ${ }^{9}$ For this study a meal was defined as the consumption of over $1.255 \mathrm{MJ}$ in 30 minutes.

Six volunteers (three men, three women) consumed a fibre free diet for 48 hours and flatus was collected during the last 24 hours. The liquid, Fortisip (Cow \& Gate, Trowbridge, Wiltshire), was drunk through a straw from $200 \mathrm{ml}$ bottles (each bottle had an energy value of $1 \cdot 255 \mathrm{MJ}$. No other food was allowed except tea without milk.

\section{GAS ANALYSIS}

The gases were evacuated from the bag into a greased glass syringe, and the volume was noted. Hydrogen concentration was determined (after serial dilution with room air) using an electrochemical cell in a hydrogen monitor (GMI, Renfrew). Methane and carbon dioxide content were determined using a gas chromatograph (model F30; Perkin Elmer, Beaconsfield, Buckinghamshire) fitted with a metal column $(4 \mathrm{~m} \times 2 \mathrm{~mm})$ filled with Porapak $Q$ at $32^{\circ} \mathrm{C}$ using oxygen free nitrogen as carrier gas at a flow rate of $40 \mathrm{ml} / \mathrm{min}$, a katharometer set at $100^{\circ} \mathrm{C}$, an injection temperature of $100^{\circ} \mathrm{C}$, and an injection volume of $5 \mathrm{ml}$. The output was displayed on a chart recorder (model 9176; Varian, Darnstadt) and the system was calibrated with standard mixtures of two different concentrations of each gas (Phase Sep, Queensferry, Clwyd).

Percentage concentrations were converted to volumes by multiplying by the total volume of the collection. The volumes were further converted to hourly production rates when necessary.

\section{STATISTICAL SIGNIFICANCE}

The significance of differences between sets of results was analysed by Wilcoxon's rank sum tests.

\section{Results}

\section{TOTAL VOLUME AND COMPOSITION}

The total 24 hour volume of flatus produced varied widely among subjects from 476 to $1491 \mathrm{ml}$ (median $705 \mathrm{ml}$; Fig 1). There was no significant difference in the volumes generated by men and women (median 736 and $583 \mathrm{ml}$ respectively; $p>0.05$ ). The size of individual flatus emissions could be roughly calculated for each volunteer by dividing the daytime volume (median $574 \mathrm{ml}$ ) by the number of episodes of flatulence experienced (median 8); this gave a range of volumes of $33-125 \mathrm{ml}$ (median $90 \mathrm{ml}$ ) per episode.

There were no correlations between total flatus volume and the dietary intake of energy, dietary fibre, and fat in the 24 hours preceding or the 24 hours during the test (all $p>0.05$ ). There was also no relation between the number of episodes of flatulence noticed and either the total volume of flatus collected or the volume produced during the period when the subjects were awake (both $\mathrm{p}>0.05$ ).

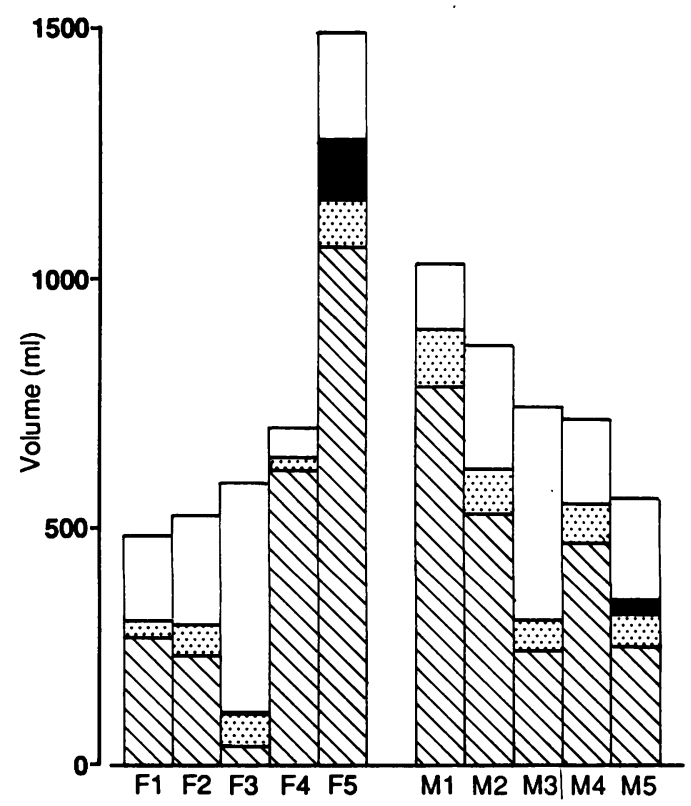

Figure 1: Individual values $(n=10)$ for the total volume of gas collected in 24 hours. Hatched bars indicate the total volume of hydrogen, spotted bars carbon dioxide, dark bars methane in hydrogen, spotted bars carbon dioxide, dark bars methane in
three subjects $(F 3, F 5, M 5)$, and the remaining blank bar represents the volume of unidentified gas (probably nitrogen). 


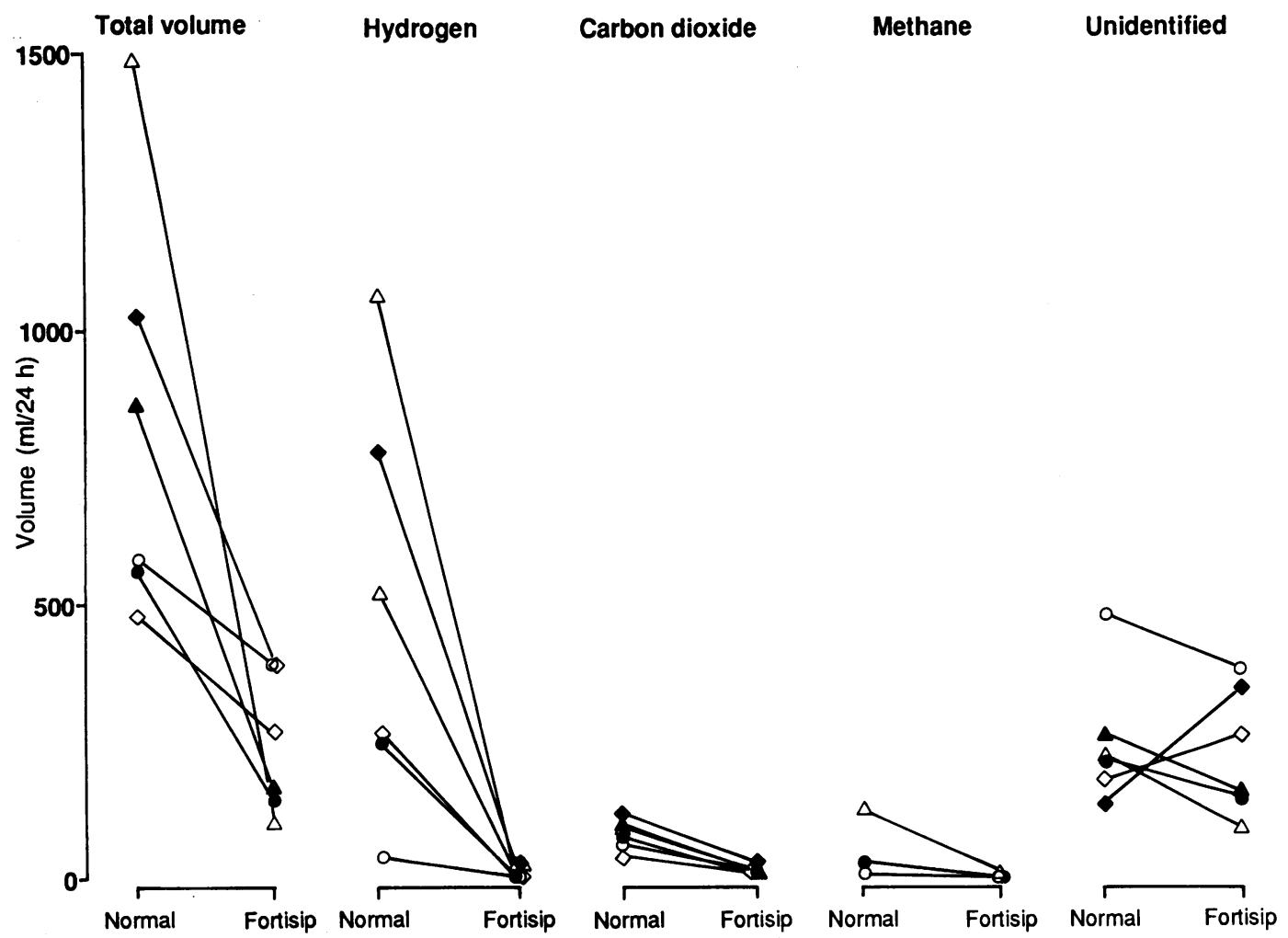

Figure 2: Individual comparisons $(n=6)$ of the total volume of all gas, hydrogen, carbon dioxide, methane, and unidentified gas produced during 24 hours on a normal diet and 24 hours on a fibre free (Fortisip) diet.

The total daily volumes of hydrogen and carbon dioxide showed considerable variation among individuals (Fig 1), with hydrogen making up over half of the total volume in five volunteers. Three volunteers produced detectable amounts of methane (Fig 1, volunteers F3, F5, and M5): 3,26 , and $128 \mathrm{ml} / 24 \mathrm{~h}$. In all subjects a proportion of the gas collected was not accounted for by the sum of hydrogen, carbon dioxide, and methane (Fig 1); this was presumably nitrogen as this would not be detected on the chromatograph used, and no peaks corresponding to the presence of oxygen were observed. The unidentified gas (presumably nitrogen) was predominant in the total volume collected for two volunteers but the median overall contribution to 24 hour flatus volume from this gas was $33 \%$ of the total.

All the collections of over $80 \mathrm{ml} / \mathrm{h}$ were composed almost entirely of fermentation gases, hydrogen, carbon dioxide, or methane, or a combination (median fermentation gas content $98.9 \%$ ), with the major contribution coming from hydrogen (median content $86 \cdot 4 \%$ ). Smaller volume collections tended to contain a lot less of fermentation gases and a higher proportion of the unidentified gas.

\section{DIURNAL VARIATION}

Flatus production fluctuated widely throughout the day and night. Three subjects seemed to produce the greatest volume in the morning, three in the afternoon, one in the evening, and one during the overnight collection. Large volume collections tended to follow meals; 13 out of a total of 22 collections of over $60 \mathrm{ml} / \mathrm{h}$ occurred in the hour after a meal compared with five collections during the hour before $(p<0.05)$.
Flatus was released while the volunteers were asleep, although the production rate during sleep (median $16 \mathrm{ml} / \mathrm{h}$ ) was significantly lower than the daytime production rate (median $34 \mathrm{ml} / \mathrm{h}$; $\mathrm{p}<0.05$ ).

The first collections of the morning that were over $30 \mathrm{ml} / \mathrm{h}$ contained significantly less fermentation gas than other collections of this size (median $17 \%$ and $38 \%$ of the total respectively; $\mathrm{p}<0.05)$.

\section{FIBRE FREE DIET}

Ingestion of the liquid diet that contained no complex polysaccharides significantly reduced the total daily volume of flatus produced $(\mathrm{p}<0.05$; Fig 2$)$ to a median of $214 \mathrm{ml}$. This was around a third of the volume produced on the normal diet by these volunteers (median $723 \mathrm{ml} / 24 \mathrm{~h}$ ). The diet also reduced the number of episodes of flatulence recorded (median $1.5 / 24 \mathrm{~h}$ and $9 / 24 \mathrm{~h}$ on Fortisip and normal diet respectively; $p<0.05$ ) and the number of collections of over $30 \mathrm{ml} / \mathrm{h}$ (median 1.5 and 7 collections/24 $h$ on Fortisip and the normal diet respectively; $\mathrm{p}<0.05$ ).

Hydrogen was almost eliminated from the flatus (Fig 2; $<<0.05$ ); less than $1.3 \mathrm{ml} / 24 \mathrm{~h}$ was produced by all subjects except one, who produced only $21 \mathrm{ml}(<3 \%$ of their production on the normal diet). The total volume of carbon dioxide was also significantly reduced to between 2 and $26 \mathrm{ml} / 24 \mathrm{~h}$ (median $6 \mathrm{ml} / 24 \mathrm{~h} ; \mathrm{p}<0.05$ ). Methane production was also abolished in the two subjects who produced the lowest volumes, whereas the higher volume produced still generated $6 \mathrm{ml}(<5 \%$ of their production on the normal diet). The volume of unidentified gas $(207 \mathrm{ml} / 24 \mathrm{~h}$ ) was remarkably similar to the value 
for these six volunteers on their normal diets (213 ml/24 h; p>0.05).

In four subjects the time of peak gas production was around the same time of day as that observed on the normal diet. The flatus production rates during both the sleeping period (median $2 \mathrm{ml} / \mathrm{h}$ ) and the daytime period (median $13 \mathrm{ml} / \mathrm{h}$ ) were dramatically reduced compared with the rates on the normal diet (median $16 \mathrm{ml} / \mathrm{h}$ and $34 \mathrm{ml} / \mathrm{h}$ respectively; both $\mathrm{p}<0.05$ ). There was no significant difference between the rate of gas production during the day and during the night on the Fortisip diet $(\mathrm{p}>0.05)$.

\section{Discussion}

This study has confirmed the variability of flatus production; the total volumes of gas expelled by the volunteers are similar to values reported by other workers, which on normal or unspecified diets range from 200 to $2460 \mathrm{ml} / 24 \mathrm{~h}^{2{ }^{210} \mathrm{We}}$ could detect no significant influence of gender on total flatus volume, although admittedly the numbers were small and there were large intersubject variations. The lack of relation between flatus volume and 'dietary fibre' ingestion may reflect bacterial adaptation to a certain intake of complex polysaccharides. The evidence for bacterial adaptation, however, is controversial; in one study a change in bacterial metabolism resulted in lower breath hydrogen release after seven days of lactulose ingestion $(40 \mathrm{~g} / \mathrm{d}),{ }^{11}$ but in another no change was seen in the volume of flatus collected regularly during the ingestion of $380 \mathrm{~g} / \mathrm{d}$ red kidney beans (cooked mass) for 23 days, ${ }^{12}$ while a third study showed no significant difference in the hydrogen and carbon dioxide produced during in vitro incubation of bran with faeces from habitual bran eaters and bran abstainers. ${ }^{13}$

The lack of a relation between the number of flatulent episodes and the total flatus volume, or the daytime flatus volume, suggests that the size of single emissions varies among individuals, probably because different people have different sensitivities to gaseous distension of the rectum. ${ }^{14}$ The size of individual discharges has been estimated as between 25 and $100 \mathrm{ml} .^{2}$ The rough calculation of the size of flatus emissions in our studies gave a range of volumes from 33 to $125 \mathrm{ml}$ (median $90 \mathrm{ml}$ ) per episode, which is similar to these previous estimates.

In most of our subjects fermentation gases made the major contribution to total daily flatus volume. Hydrogen and carbon dioxide were the main gases produced, but three out of 10 subjects produced methane. This proportion corresponds to previous reports that methanogenesis occurs in between $33 \%$ and $50 \%$ of the normal population. ${ }^{15}$

Around one third of the total volume of flatus produced was the unidentified gas, presumably nitrogen. The source of the nitrogen may be swallowed air, ${ }^{16}$ or gas which has diffused from the blood into the intestinal lumen, ${ }^{17}$ or it may even be derived from the bacterial breakdown of amino acids. ${ }^{18}$ Although bacterial production of nitrogen has been observed in vitro, the contribution to flatus from this source is thought to be insignificant under normal conditions; the ratio of argon:nitrogen has been measured in flatus and was found to be slightly lower than in air, indicating that there had been no dilution by bacterially produced nitrogen. ${ }^{18}$ Nitrogen should tend to equilibrate between the lumen and venous blood where the concentration is around $80 \%$, but its rate of diffusion through the epithelium is extremely slow compared with the other gases present, ${ }^{17}$ so that once it has entered the gut it is unlikely that any substantial amount would be reabsorbed. Nitrogen concentrations in flatus collections that are higher than $80 \%$ arise when it is trapped and concentrated in the lumen due to the more rapid absorption of other gases and possibly therefore reflect a slower passage of gas through the colon allowing more extensive absorption and bacterial use of the fermentation gases.

Large volume collections consisted almost entirely of fermentation gases, probably reflecting a higher rate of gas production from the colonic bacteria and rapid passage through the colon.

The hydrogen concentration recorded in our collections is higher than that reported by others. One reason for this is that most workers collect for longer periods and quote an average concentration from a number of collections. Another reason is that we took great care to minimise leakage by the use of totally gas impermeable collecting apparatus. The low volumes of unidentified gas (presumably nitrogen) suggest that contamination and leakage were minimal in our collection system.

The observation that large collections occurred more frequently after the consumption of a meal indicates a greater interaction between substrate and bacteria after meals. Ingestion of a meal is followed within an hour by an increase in colonic motility, the so called gastrocolic response. ${ }^{19}$ This may increase gas production by mixing substrate with metabolically active bacteria, and may also increase gas expulsion by stimulating propulsive movements. ${ }^{20}$ We have previously suggested that the rise in breath hydrogen concentration that occurs immediately after ingesting a meal may be related to evacuation of the unabsorbed carbohydrate residues of the previous meal from the ileum into the colon. ${ }^{21}$

Smaller collections, which correspond to a slower rate of release, contain lower concentrations of fermentation gas, and probably reflect a low production rate and slower transit through the colon allowing more extensive diffusion of fermentation gas from the lumen into the bloodstream. Steggerda also observed that the per cent nitrogen content varied inversely with the rate of passage of flatus. ${ }^{22}$

The reduction in the production rate of flatus during the night may be explained by the reduction in colonic motility during sleep. ${ }^{+}$This is supported by the fact that the first large collections of the morning contained significantly less fermentation gas than other collections of this size, suggesting that early morning collections represent the expulsion of gas that has accumulated during the night when a lack of motility allows extensive diffusion of hydrogen 
and carbon dioxide into the blood and nitrogen into the lumen.

The 'fibre free' diet practically eradicated the fermentation gases, particularly hydrogen. Other workers have noted that the hydrogen concentration of flatus decreases to negligible levels after taking a 'formula' (fully absorbable) diet for three days ${ }^{23}$ and suggest that fermentation of endogenous substrates such as mucins produces little hydrogen. Indeed less hydrogen was produced when mucins were infused into the colon compared with lactulose $(2$ and $7.6 \mathrm{ml}$ hydrogen/g substrate respectively), ${ }^{24} 25$ but the slower and more constant fermentation of mucins when other substrates are absent on an elemental diet may allow hydrogen to diffuse into the blood and be excreted in the breath rather than in flatus. Indeed breath hydrogen concentrations during the study with the 'formula' diet were consistently well above zero. ${ }^{23}$

Carbon dioxide was still present with the Fortisip diet but at a lower level than with the normal diet. The concentration of $1 \cdot 4-6.7 \%$ was similar to that observed by Calloway and Murphy of around $6 \%,{ }^{23}$ and probably reflects the fact that this gas can rapidly equilibrate with the venous blood which has a mean carbon dioxide content of around $6 \cdot 86 \% .{ }^{17}$

The observation that the quantity of nonfermentation gas was remarkably similar with the 'fibre free' and the normal diets is surprising as the liquid diet was sipped through a straw, which is thought to increase air swallowing. ${ }^{16}$ If, as seems likely, the gas is nitrogen, then the source may differ according to the diet. The nitrogen in flatus on a normal diet is probably mainly due to diffusion from the blood in response to a reduced partial pressure in the gut lumen owing to the production of fermentation gases.

Fermentation gases make up around two thirds of normal flatus volume when subjects ingest a normal diet, and they can be eradicated by the ingestion of a 'fibre free' diet, leaving a residual gas release of around $200 \mathrm{ml} /$ day.

1 Sutalf LO, Levitt MD. Follow-up of a flatulent patient. Dig Dis Sci 1979; 24: 652-4.
2 Lasser RB, Bond JH, Levitt MD. The role of intestinal gas in functional abdominal pain. $N$ Engl F Med 1976; 293: 524

3 Kirk E. The quantity and composition of human colonic flatus. Gastroenterology 1949; 19: 782-94.

4 Calloway DH, Burroughs SE. Effect of dried beans and silicone on intestinal hydrogen and methane production in man. Gut 1969; 10: 180-4.

5 Narducci F, Bassotti G, Gaburri M, Morelli A. Twenty-four hour manometric recording of colonic motor activity in heal thy man. Gut 1987; 28: 17-25.

6 Beazell JM, Ivy AC. The quantity of colonic flatus excreted by the 'normal' individual. American Fournal of Digestive Diseases 1941; 8: 128-9.

7 Askevold F. Investigations on the influence of diet on the quantity and composition of intestinal gas in humans. Scand f Clin Lab Invest 1956; 8: 87-94.

8 Perman JA, Modler S. Glycoproteins as substrates for production of hydrogen and methane by colonic bacterial flora. Gastroenterology 1982; 83: 388-93.

9 Paul AA, Southgate DAT, eds. MCCance $\mathcal{E}$ Widdowson's the composition of foods. London: HMSO, 1978.

10 Blair HA, Dern RJ, Bates PL. The measurement of the volume of gas in the digestive tract. Am $\mathcal{F}$ Physiol $1947 ; 149$ 688-707.

11 Florent C, Flourie B, Leblond A, Rautreau M, Bernier J-J, Rambaud J-C. Influence of chronic lactulose ingestion on the colonic metabolism of lactulose in man (an in vivo study). $\mathcal{7}$ Clin Invest 1985; 75: 608-13.

12 O'Donnell AU, Fleming SE. Influence of frequent and longterm consumption of legume seeds on excretion of intestinal gases. Am $\mathcal{F}$ Clin Nutr 1980; 40: 48-58.

13 Bond JH, Levitt MD. Effect of dietary fibre on intestinal gas production and small bowel transit time in man. Am $\mathcal{F}$ Clin Nutr 1978; 31: S169-74.

14 Sun WM, Read NW. Anorectal function in normal human subjects: effect of gender. Int 7 Colorect Dis 1989; 4: 188-96.

15 Pitt $P$, De Bruin KM, Beeching MF, Goldberg E, Blendis KM. Studies on breath methane: the effects of ethnic origins KM. Studies on breath methane: the
and lactulose. Gut 1980; 21: 951-9.

16 Roth JLA, Bockus HL. Aerophagia: its etiology, symptoms and management. Med Clin North Am 1957; 41: 1673-96.

17 Pogrund RS, Steggerda FR. Influence of gaseous transfer between the colon and bloodstream on percentage gas composition of intestinal flatus in man. Federation Proceed ings 1948; 153: 475-82.

18 Calloway DH, Colasito DJ, Mathews RD. Gases produced by human intestinal microflora. Nature 1966; 212: 1238-9.

19 Snape WJ, Matarazzo SA, Cohen S. Effect of eating and gastrointestinal hormones on human colonic myoelectrical gastrointestinal hormones on human colonic myoelectr
and motor activity. Gastroenterology 1978; 75: 373-8.

20 Moreno-Ossett E, Bazzocchi G, Lo S, et al. Association between post-prandial changes in colonic intraluminal pressure and transit. Gastroenterology 1989; 96: 1265-73.

21 Read NW, AlJanabi MN, Bates TE, et al. Interpretation of the breath hydrogen profile obtained after ingesting a solid meal containing unabsorbable carbohydrate. Gut 1985; 26: 834 42.

22 Steggerda FR. Gastrointestinal gas following food consumption. Ann N Y Acad Sci 1968; 150: 57-66.

23 Calloway DH, Murphy E. Intestinal hydrogen and methane of men fed space diet. Life Science and Space Research 1969; 7 102-9.

24 Flourie B, Pellier P, Florent C, Franchisseur M, Maurel JC, Rambaud JC. Site of $\mathrm{H}_{2}$ and $\mathrm{CH}_{4}$ production in response to a load of endogenous glycoprotein in normal man. Gastroenterology 1987; 93: 1393.

25 Florent C, Flourie B, Pellier P, Maurel M, Leblond A Rambaud JC. Site of $\mathrm{H}_{2}$ and $\mathrm{CH}_{4}$ production in response to lactulose load in normal man. Gastroenterology 1987; 92: 1392. 